Parents' Creativity Self-Beliefs

\title{
Parents' Creative Self-Beliefs and Creative Activity as Predictors of Family Lifestyle
}

\author{
Izabela Lebuda ${ }^{1}$, Dorota M. Jankowska², Maciej Karwowski ${ }^{1}$ \\ ${ }^{1}$ Institute of Psychology, University of Wroclaw, Poland \\ ${ }^{2}$ The Maria Grzegorzewska University, Poland
}

Authors' Note and Acknowledgement

Izabela Lebuda (ID https://orcid.org/0000-0002-4715-1928, Institute of Psychology, University of Wroclaw, Poland. Dorota M. Jankowska, (D) https://orcid.org/0000-0003-3758-5914, Department of Educational Sciences, The Maria Grzegorzewska University, Poland, Maciej Karwowski, https://orcid.org/0000-0001-6974-1673, Institute of Psychology, University of Wroclaw.

This study was supported by funding obtained from National Science Centre (UMO2017/27/B/HS6/00592) for Dorota Maria Jankowska, The Maria Grzegorzewska University, Szczesliwicka 40 Street, 02-353 Warsaw, Poland, e-mail: dorotamariajankowska@gmail.com

The authors declare that there is no conflict of interest regarding the content of this article.

\section{Author Contributions:}

Izabela Lebuda: data collection, data preparation, report writing;

Dorota M. Jankowska: study conceptualization, data collection, data preparation, report writing; Maciej Karwowski: data preparation, data analysis, report writing. 


\section{Abstract}

Family rules, routines, and resources shape children's creativity. However, little is known about how parents' creative self-beliefs and creative activity are related to the lifestyle adults create in their families. Family lifestyle might be operationalized as referring to domain-general dimensions of family functioning (cohesion, flexibility, communication, and family satisfaction) and domain-specific factors related to creativity (encouragement to experience novelty and varieties; encouragement to nonconformism; support of perseverance in creative efforts; encouragement to fantasize). To explore the link between parents' creativity-related characteristic and family lifestyle, 303 Polish parents (57\% mothers) of children aged between 6 and $10(M=7.99 ; S D=1.38)$ reported on their creative self-beliefs, creative activity, overall family characteristics, and climate for creativity in their families. We found that both parents' creative self-beliefs (creative self-efficacy and creative personal identity) and their creative activity predict support for creativity in the family and more general balanced and satisfying family relationships. We discuss these findings, point new paths for future research, and suggest interventions in regards to the family creativity-fostering environment.

Keywords: creative activity; creative self-beliefs; family climate for creativity; family social functioning; family cohesion 


\section{Parents' Creative Self-Beliefs and Creative Activity as Predictors of Family Lifestyle}

Environmental factors have a crucial role in creative development (Lebuda \& Glăveanu, 2019; Lebuda et al., in press). From early works (e.g., Goertzel et al., 1978; Harrington et al., 1987; Michel \& Dudek, 1991; Miller \& Gerard, 1979; Rogers, 1954; Wright \& Wright, 1986) to more recent research (e.g., Gralewski \& Jankowska, 2020; Gute et al., 2008; Jankowska \& Karwowski, 2019; Karwowski et al., 2020; Pang et al., 2020; Si et al., 2018) parents' influences on children's creativity are considered obvious. However, little is still known about parents' specific psychological characteristics and behaviors that might be key to creating a family environment that supports development of abilities, beliefs, and attitudes conducive to children's creativity.

Although previous studies demonstrated that caregivers' personality plays a role in explaining their parental styles and relationship with children (e.g., Kochanska et al., 2004; Maccoby, 1992; Prinzie et al., 2009; Skinner et al., 2005), little is known about individual differences factors that are related with family creative lifestyle (see Kwaśniewska et al., 2018; Kwaśniewska \& Lebuda, 2017, for exception). The so-called creative self-beliefs that might relate to everyday family practice and intentional effort to support children's creativity might form a promising set of traits. The main aim of the present research is to fill this gap and examine how creative self-beliefs of parents, responsible for agentic functioning (Karwowski et al., 2019), and parents' creative activities, are related to the family lifestyle/environment.

\section{Parental Creativity-Related Characteristics}

\section{Parents' Creative Self-Beliefs}

People's goals, choices, and actions are driven by their beliefs (Bandura, 1997). In recent decades, it has been pointed out that creativity depends not only on creative abilities but also on creative self-beliefs (CSB; Karwowski et al., 2019). Creative self-beliefs describe people's convictions about creativity (for a discussion, see Beghetto \& Karwowski, 2017). They could be organized into three broad categories: creative confidence beliefs, creative self-awareness beliefs, and creative self-image beliefs (Karwowski 
et al., 2019). In the study we present below, we focus on two aspects of creative self-beliefs: creative self-efficacy (Beghetto, 2006; Tierney \& Farmer, 2011) and creative personal identity (Jaussi et al., 2007; Karwowski et al., 2013). Creative self-efficacy (CSE) is one of the creative confidence beliefs, a conviction that "one has the ability to produce creative outcomes" (Tierney, \& Farmer, 2002, p. 1138) and refers to “a person's perceived confidence to creatively perform a given task, in a specific context, at a particular level (Karwowski et al., 2019, p. 398). This belief is highly malleable and influenced by sociocognitive and environmental factors (Bandura, 1997). Creative confidence mediates the relationships between creative potential and creative behavior (Beghetto et al., 2020; Chen, 2016; Choi, 2004). People who believe in their creative abilities are more engaged in creative tasks and challenges (Carmeli \& Schaubroeck, 2007; Pretz \& McCollum, 2014; Tierney \& Farmer, 2002; Tierney \& Farmer, 2011). While previous investigations demonstrated that eminent creators' mothers were highly selfconfident (Goertzel et al., 2004), we could not find any research about caregivers' creative self-efficacy and their everyday behavior that may support children's creativity. However, this link was quite intensively studied in the case of teachers (see Bereczki \& Kárpáti, 2018 for discussion). Indeed, several studies have found that teachers with high self-efficacy and high creative self-efficacy are more prone to promoting students' creativity and use teaching styles that support creativity (e.g., Cayirdag, 2017; Dilekli \& Tezci, 2016; Ozkal, 2014). Therefore, it could be assumed that parents who believe in their ability to deal with creative challenges will put more effort into creating a family lifestyle conducive to the children's creative development.

To act creatively, people not only have to be confident in their abilities but also perceive creativity as important (Karwowski \& Beghetto, 2018). Creative self-image beliefs, especially creative personal identity (CPI) describe how someone values creativity and how significant this ability is for the sense of self (Beghetto \& Karwowski, 2017; Jaussi et al., 2007; Plucker \& Makel, 2010) . Valuing creativity seems crucial for the decision to involve in creativity (Sternberg, 2002). Creative actions help 
to achieve a congruent self-image as a person for whom creativity is an integral part of personal identity (see, e.g., Freeman, 1993; Petkus, 1996). Valuing creativity moderates the relation between creative potential and creative behavior (Karwowski \& Beghetto, 2018), so to employ creativity in any area of life, also in the everyday family context, people have to be confident in their abilities but also perceive creativity as essential and valuable.

It is known that parents' general self-image translates into parental styles and family climate (Sigel et al., 1984). In the case of parents' creative self-image, we managed to find only a few premises about their role for a creative lifestyle. The first one is that parents with a positive attitude towards creativity and positive value of creative child characteristics are more prone to nurture children's creativity (Pugsley \& Acar, 2018). An indirect link between creative self-image and family life was also presented in the qualitative analysis of eminent creators' experience. It has been shown that beliefs about the importance of creativity in one's life and perceiving creator's role are primarily related to how highly creative people fulfill family roles (Lebuda \& Csikszentmihalyi, 2020). However, this research mainly focused on the role of being a spouse or a partner, less so on being a parent. Also, in qualitative analyses it was shown that mothers who valued creativity associated it mainly with a specific lifestyle and personal life and less so on professional creative activities. Their creative functioning tended to focus on two main areas: building a flexible, empathic relation with the child and creating a climate conducive to the child's creative development (Kwaśniewska \& Lebuda, 2017).

\section{Parent's Creative Activities}

Creative activity refers to all levels of creativity, from generating ideas or preparing a new meal, through professional problem-solving, to socially recognized creative achievements like publishing a book (Beghetto \& Kaufman, 2007; Kaufman \& Beghetto, 2009). It was even pointed out that "the conduct of life in itself can be a creative act" (Tanggaard, 2015, p. 181). Everyday life actions, relations with others, and dealing with daily duties and unexpected challenges often need improvisation and creativity. This 
kind of activity, usually called everyday creativity, refers to non-eminent, non-professional behaviors defined in terms of "human originality at work and leisure across the diverse activities of everyday life" (Richards, 2010, p. 190). In this perspective, arranging family life and supporting children's development could be a creative activity (see Kwaśniewska \& Lebuda, 2017). Parenthood, besides mating and work, is one of the primary forms of an adult person's creative form of expression (Karwowski \& Wiśniewska, in press). Parents agree that their children are a source of inspiration and that parenthood makes them more creative (Dillon, 2002). In the case of people for whom creativity is essential, parenthood lets them fulfill their creative needs and helps to manage their family duties, work, and personal life, as well as to deal effectively with various demands associated with different social roles (Kwaśniewska \& Lebuda, 2017). Therefore, parents' creativity is mostly linked to the efficiency of solving problems and challenges in an unusual way (Kwaśniewska \& Lebuda, 2017).

Classic studies have found that mothers of highly creative children were often deeply involved in their careers and had active and independent life (MacKinnon, 1962). At the same time, mothers of more creative children felt more self-fulfilled at home and more accomplished at work than mothers of less creative ones (Michel \& Dudek, 1991). The different relations between parenthood and creative activities is illustrated by a typology derived from biographies of acclaimed female artists (Miller, 2010). Five types of relationships were pointed out: (1) give up parenthood in favor of creative work; (2) being a parent but focus on own creative development, limit taking care of a child to a minimum; (3) focus mainly on parenthood and limit or withdraw from creative activities at all; (4) tire to balance parenting with outside family creative activities; (5) engage in parenthood and other creative activities sequentially (Miller, 2010). It might be expected that parents who are more creative in everyday life will also establish a more creative family environment. Still, however, it is equally possible that if they engage in family life, they will abandon outside-family creative activities.

\section{The Creative Lifestyle}


We define the creative lifestyle as a family's everyday practice and interpersonal relationships, especially communication tendencies, which directly and indirectly support creative development of all family members. Two main areas that constitute the creative lifestyle are (1) domain-general: the social functioning of the family and (2) domain-specific: climate for creativity in the parent-child relationship.

\section{Family Social Functioning}

Apart from building family climate, making relations with children is an essential creative parental activity (Kwaśniewska \& Lebuda, 2017). One of the most popular theories and assessment of family social performance (Kouneski, 2000) is reflected in the Circumplex Model of Marital and Family Systems (Olson et al., 2019). The model consists of two main dimensions: cohesion and flexibility. Cohesion (togetherness) describes the emotional bonding between family members (Olson, 2011). Emotional closeness, time spent together, a common form of relaxation, and decision-making consulted with each other are some indicators of cohesion in a family. The spectrum of cohesion is from enmeshed, through connected, separated, to disengaged. Flexibility describes how stability is balanced with a change in a family (Olson, 2011). The spectrum of flexibility is from chaotic, through flexible, structured, to rigid. Some indicators of flexibility in a family are that all family members participate in making rules; a family looking for new ways of dealing with challenges. Main hypotheses derived from the Circumplex Model are that balanced families are more functional, have more positive communication, and more effectively modify their cohesion and flexibility to deal with changes and challenges. Cohesive families balance between separateness and togetherness: Family members are both independent and connected to family. High cohesion level means too little independence in family, too low means limited attachment to it. High level of flexibility could lead to chaos, and low level of flexibility could lead to rigidity. A balanced family is structured and flexible at the same time.

Two additional factors of the model are communication and family satisfaction (Olson, 2011). Communication helps alter the appropriate level of cohesion, and flexibility allows us to deal with 
challenges, facilitate, and maintain a balanced relationship. Family satisfaction indicates how much each family member likes the current family system.

A few previous studies investigated the links between the Circumplex Model of family functioning and children's creative potential. It was observed that freshman college students obtain the highest self-report creativity from highly adaptable families and the lowest by ones from rigid families (low adaptability) (Gardner \& Moran, 1990). Family cohesion was not particularly important for creativity. The authors speculate that while growing in adaptable families (flexible and even chaotic), people can make their own mistakes, learn from them, and develop creativity (Gardner \& Moran, 1990).

A study on preschool children's creative potential and family social functioning results indicated that children from more flexible families had slightly higher scores on originality, while children from more cohesive (enmeshed) families were less likely to score high on creativity measures (Bomba et al., 1991). However, high family cohesion was also a positive predictor of perceived own creativity among gifted Chinese students (Chan, 2005). The difference in results could be a matter of cultural difference but it could also be derived from different measures applied.

\section{Climate for Creativity in Family}

Climate for creativity in the parent-child relationship is defined as "parents' overall relatively constant behavioral pattern that helps the child acquire a mindset, attitudes, personal qualities, and skills necessary for creativity" (Kwaśniewska et al., 2018, p. 14). It is a stable pattern of parents' attitudes and behaviors toward children aimed at enhancing creativity. Four key factors of climate for creativity in a parent-child relationship were identified to-date: encouraging the pursuit of novel and varied experience, supporting a nonconformist attitude and independence, strengthening perseverance in the performance of creative tasks, and encouraging, supporting fantasizing (Kwaśniewska et al., 2018; Kwaśniewska \& Lebuda, 2017). They all are instrumental in strengthening children's overall development, with a particular focus on creativity development. Gaining novel and diversified 
experiences constitute a form of the cultural capital of a child that enhances creativity by stimulating new ideas and interests (e.g., Goertzel et al., 2004; Gute et al., 2008; Tennent \& Berthelsen, 1997). Independence and nonconformism were important predictors of creative activity and achievements (e.g., Batey \& Furnham, 2006). The same applies to perseverance - crucial for creative achievement (Abuhassàn \& Bates, 2015), with a unique role played by parents in modeling this kind of behavior (e.g., Gute, et al., 2008). The last factor is parental active support of children's fantasizing. Indeed, it has been demonstrated that creative imagination is one of the crucial creative abilities (Glăveanu, et al., 2017; Karwowski \& Jankowska, 2016), and play combined with the fantasy is one of the predictors of adult creativity (Russ et al., 1999).

It has been shown that Big Five personality traits predict the climate for creativity in mothers' relationship with children (Kwaśniewska et al., 2018). All four creative climate dimensions were predicted by mothers' openness to experience. Additionally, encouragement for children to seek novelty and variety was positively related to mothers' emotional stability, conscientiousness, and extraversion, while supporting a nonconformist attitude and independence was negatively predicted by conscientiousness. Strengthening perseverance in the performance of creative tasks was linked to mothers' emotional stability, conscientiousness, agreeableness, extraversion.

In conclusion, it has been shown that personality and creative self-beliefs are related yet separate constructs (Karwowski \& Lebuda, 2016, 2017). Thus we decide to examine how parents' creative selfefficacy and their creative personal identity link with four factors of family climate for creativity. Because it was shown that aspects of the family climate for creativity relate with the constructive parenting style - parental acceptance and autonomy granting (Jankowska \& Gralewski, under review) - we also expect that they will be connected to family social functioning.

\section{The Present Study}


The purpose of this study is to examine how parent-related factors (parents' creative self-beliefs and parents' creative activities) are linked to family lifestyle. Family lifestyle refers to essential dimensions of family functioning (cohesion, flexibility, communication, family satisfaction) and the climate for creativity in a parent-child relationship (encouragement to experience novelty and varieties; encouragement to nonconformism; support of perseverance in creative efforts; encouragement to fantasize). Below is a detailed description and discussion of the present study.

\section{Method}

\section{Participants}

In the analysis, we include data from 303 Polish parents (41\% fathers, 57\% mothers, $2 \%$ others) of children between 6 and 10 years of age $(M=7.99 ; S D=1.38)$. Mothers' age ranged from 23 to 53 ( $M$ $=37.32, S D=5.77$, fathers' from 27 to $64(M=40.10, S D=6.52)$.

\section{Measures}

The Short Scale of Creative Self (SSCS; Karwowski et al., 2018)

SSCS was used to assess parents' creative self-beliefs. The instrument consists of eleven items. Six items measure creative self-efficacy (CSE) (example: I know I can efficiently solve even complicated problems, $\alpha=.92$ ). Five items are dedicated to assessing creative personal identity (CPI) (example: $M y$ creativity is important to who I am, $\alpha=.91$ ). A 7-point scale was used: $1=$ definitely not, $7=$ definitely yes.

The Inventory of Creative Activities and Achievements (ICAA; Jauk, Benedek, \& Neubauer, 2014). A modified version of the ICAA (activity scale only) was used to measure parents' creative activity. The instrument includes 33 items with creative activities in seven domains: (a) everyday (7 items), (b) web development/programming (7 items), (c) music (4 items), (d) science (4 items), (e) dance (2 items), (f) visual arts (4 items), and (g) writing (5 items). Participants reported whether they engaged in a particular activity within the last year, from $0=$ never to $4=$ more than 10 times $(\alpha=.91)$. 
Parents' creative self-belief

\section{The Climate for Creativity in Parent-Child Relationship (CCP-CRQ).}

CCP-CRQ is a 24-item instrument, measuring four dimensions of the climate for creativity in the parent-child relationship: Encouragement to Experience Novelty and Variety (example: I try to suggest to my child unconventional ways to solve problems, $\alpha=.84$ ), Encouragement of Nonconformism (example: I do not want my child to stand out from the group $(\alpha=.83)$, Support of Perseverance in Creative Efforts (example: When my child has problems I support and motivate him/her to see many solutions, $\alpha=.93$ ), and Encouragement to Fantasize (example: I sometimes engage my child in my "weird" ideas, $\alpha=.80$ ) (Kwaśniewska, 2019). Each scale consists of six items, each using a seven-point response scale (1 = entirely disagree; 7 = entirely agree).

FACES IV Flexibility and Cohesion Evaluation Scales.

A Polish adaptation (Margasiński, 2015) of Faces IV was used to measure family social functioning. This 62-item instrument consists of six basic scales (7 items each); two balanced: balanced cohesion (example: Family members are involved in each other's lives, $\alpha=.78$ ), balanced flexibility (example: Our family tries new ways of dealing with problems, $\alpha=.70$ ); 4 unbalanced: disengaged (example: We get along better with people outside our family than inside, $\alpha=.81$ ), enmeshed (example: We spend too much time together, $\alpha=.76$ ), rigid (example: There are strict consequences for breaking the rules in our family, $\alpha=.63$ ), and chaotic (example: We never seem to get organized in our family, $\alpha=$ .77). Two additional scales (10 items each) are family communication (example: Family members are satisfied with how they communicate with each other, $\alpha=.94)$ and family satisfaction (The degree of closeness between family members, $\alpha=.92$ ). Responses are provided on a 5-point Likert scale (from $1=$ I completely agree, to $5=$ I completely disagree).

\section{Control Variables}


In all analyses, we controlled for parents' sex, age, education level, self-esteem of material situation ( $1=$ only for the basic needs, $5=$ we have earnings, $M=2.45 ; S D=1.09$ ) as well as the number of children $(\min =1, \max =5, M=2.03 ; S D=0.93)$.

\section{Procedure}

The study was conducted online using the Pollster company online panel. One parent per family contributed data; all participants had one or more children between 6 and 10 years of age. Participants were informed about confidentiality of their responses and provided consent to process personal data. The protocol and procedure of the study were accepted by the Institutional Review Board of the 2nd author's university.

\section{Results}

We integrated variable- and person-centered analyses. Variable-centered analyses were conducted first. Descriptive statistics and correlations between variables used in this study are presented in Table 1 below. Creativity-related variables: CSE, CPI, and creative activity were significantly linked with positive aspects of family functioning (balanced cohesion, balanced flexibility, communication, family satisfaction) and climate for creativity (encouragement novelty, support for perseverance, encouragement fantasy) and negatively with negative aspects of family functioning (disengagement, enmeshed, chaos).

\section{Table 1.}

Descriptive Statistics and Correlations between Variables

\begin{tabular}{|c|c|c|c|c|c|c|c|c|c|c|c|c|c|c|c|c|c|c|c|c|c|}
\hline & & $M$ & SD & 2 & 3 & 4 & 5 & 6 & 7 & 8 & 9 & 10 & 11 & 12 & 13 & 14 & 15 & 16 & 17 & 18 & 19 \\
\hline & & $41 \%$ & & & & & & & & & & & & & & & & & & & \\
\hline 1 & Sex & $M$ & -- & .35 & .18 & .12 & -.12 & .12 & .01 & .03 & -.02 & .05 & .12 & .23 & .10 & .07 & .04 & .07 & .02 & .00 & -.07 \\
\hline & & 38.8 & 6.08 & & & & & & & & & & & & & & & & & & \\
\hline 2 & Age & 2 & & 1 & .26 & -.05 & .12 & -.02 & .05 & .07 & .02 & .05 & -.06 & .02 & -.07 & -.15 & .13 & .03 & .04 & .01 & -.00 \\
\hline 3 & Education & 5.47 & 1.70 & & 1 & .15 & -.15 & .11 & .09 & .15 & .09 & .05 & -.10 & -.05 & -.04 & -.03 & .08 & .09 & .16 & .05 & .05 \\
\hline 4 & Material & 3.55 & 1.09 & & & 1 & -.06 & .24 & .11 & .09 & .10 & .08 & -.03 & .00 & .00 & -.03 & .05 & .14 & .03 & .11 & -.02 \\
\hline 5 & No. of children & 2.03 & 0.93 & & & & 1 & -.02 & -.03 & -.03 & -.02 & .05 & .02 & -.04 & .12 & -.02 & .02 & .02 & -.02 & -.06 & .01 \\
\hline 6 & CSE & 0.00 & 1.00 & & & & & 1 & .00 & .20 & .29 & .37 & -.21 & -.15 & .06 & -.22 & .32 & .40 & .27 & -.09 & .23 \\
\hline 7 & CPI & 0.00 & 1.00 & & & & & & 1 & .34 & .15 & .10 & -.04 & .06 & .01 & -.13 & .20 & .29 & .19 & -.01 & .13 \\
\hline 8 & Creat. Act. & 1.60 & 0.49 & & & & & & & 1 & .18 & .14 & -.04 & .04 & .09 & -.07 & .20 & .19 & .23 & .06 & .10 \\
\hline
\end{tabular}




\begin{tabular}{|c|c|c|c|c|c|c|c|c|c|c|c|c|c|c|}
\hline 9 & Bal. Coh. & 4.07 & 0.61 & 1 & .71 & -.55 & -.31 & .07 & -.23 & .74 & .53 & .28 & -.05 & .32 \\
\hline 10 & Bal. Flex. & 3.75 & 0.59 & & 1 & -.37 & -.20 & .29 & -.22 & .64 & .46 & .28 & -.14 & .31 \\
\hline 11 & Disengag. & 2.15 & 0.79 & & & 1 & .69 & .37 & .60 & -.51 & -.41 & -.23 & .01 & -.32 \\
\hline 12 & Enmes. & 2.35 & 0.75 & & & & 1 & .48 & .58 & -.33 & -.29 & -.14 & .03 & -.23 \\
\hline 13 & Rigid & 2.90 & 0.61 & & & & & 1 & .24 & .05 & -.04 & -.03 & -.15 & -.04 \\
\hline 14 & Chaotic & 2.52 & 0.75 & & & & & & 1 & -.36 & -.32 & -.17 & .15 & -.25 \\
\hline 15 & Communic. & 3.93 & 0.76 & & & & & & & 1 & .69 & .28 & -.12 & .33 \\
\hline 16 & Family sat. & 3.63 & 0.64 & & & & & & & & 1 & .26 & -.05 & .22 \\
\hline 17 & Enc. Nov. & 5.23 & 1.11 & & & & & & & & & 1 & -.53 & .82 \\
\hline 18 & Enc. Nonc. & 2.84 & 1.09 & & & & & & & & & & 1 & -.70 \\
\hline 19 & Supp. Persev. & 5.82 & 1.16 & & & & & & & & & & & 1 \\
\hline 20 & Enc. Fantas. & 5.11 & 1,08 & & & & & & & & & & & \\
\hline
\end{tabular}

Note. $N=303$. All correlations above or equal $|.12|$ are statistically significant at $p<.05$ and are bolded.

Sex coded 1 = woman, 2 = man; $C S E=$ Creative Self-Efficacy, $C P I=$ Creative Personal Identity; Creat. Act $=$ Creative Activity; Bal. Coh. = Balanced Cohesion; Bal. Flex. = Balanced Flexibility; Diseng. = Disengagement; Enmes. $=$ Enmeshed; Rigid. = Rigidity; Chaotic $=$ Chaos; Communic. $=$ Communication; Family. Sat = Family Satisfaction; Enc. Nov. = Encouragement Novelty; Enc. Nonc. $=$ Encouragement Nonconformity; Supp. Persev. = Support for Perseverance; Enc. Fantas. = Encouragement Fantasy. CSE and CPI were saved as varimax-rotated factor analysis results.

Given the large number of correlations provided in Table 1, we also illustrated the relationships between the variables in a more readable, graphical manner. As presented in Figure 1 (left panel), when correlations are organized by their strength (hclust method in corrplot package for $\mathrm{R}$, function in Wei et al., 2017), a clear two-cluster pattern emerges. First, creative self-beliefs and creative activity were positively linked with positive family factors. In contrast, the second cluster consisted of positively correlated harmful elements: encouragement nonconformity, rigidity, chaos, disengagement, and feeling enmeshed. However, as the right panel of Figure 1 shows, three groups of variables we used in our study were still clearly and sufficiently separated, thus providing evidence that neither the common method variance nor the self-report character of the measures we used compromised the validity of our measurement.

\section{Figure 1}




\section{Pattern of Correlations between Variables (left panel) Organized by Clusters and Network Analysis}

\section{Results (right panel) of the Links between Variables Included in the Study.}
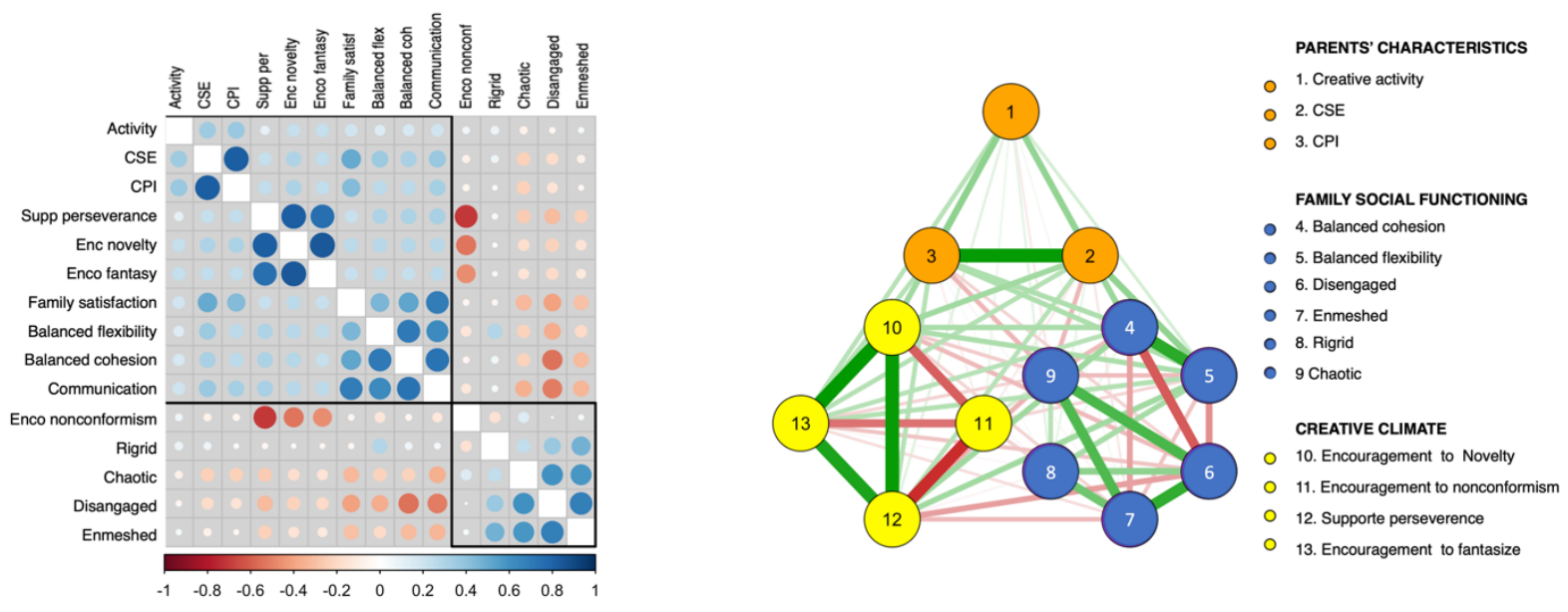

To quantify the amount of variability of family lifestyle and climate for creativity associated with parents' individual characteristics (sex, age, education), family situation (number of children and material condition of the family) as well as their creativity (CSE, CPI, and creative activity), we relied on hierarchical regression analysis. Separate models were created for each of the family lifestyle scales (See Table 2 below) and creative climate scales (Table 3). Demographic and family-related controls were introduced in Step 1, while CSE, CPI, and creative activity in Step 2.

As illustrated in Table 1, controls were generally weakly associated with family lifestyle variables. Statistically significant links were observed in the case of negative characteristics: fathers tended to be more disengaged, enmeshed, rigid, and chaotic than mothers. Higher rigidity and chaos was also typical for younger parents. Overall, family satisfaction was positively linked with the selfreported material situation of the family. Overall, however, the control variables predicted from $1 \%$ of the variability in the balanced flexibility (with a non-significant model) to $7 \%$ of feeling enmeshed in a family. 
The creativity variables introduced in the second step tended to improve the models by a $\Delta \mathrm{R}^{2}$ from $1 \%$ (feeling rigid - non-significant change) to $24 \%$ in the case of overall satisfaction with family. Creative self-efficacy was a consistent predictor of positive aspects of family lifestyle (bs from .28 in the case of balanced cohesion to .40 in the case of family satisfaction) and was negatively linked to all negative aspects of family lifestyle apart from rigidity ( $\beta$ s from -.19 in the case of feeling enmeshed to .26 in the case of the assessed chaotic situation in the family). The two remaining creativity-related variables were less consistent in predicting the family lifestyle. Creative personal identity positively predicted balanced cohesion, communication, and family satisfaction while negatively related to a chaotic lifestyle. Creative activity was unrelated to the family lifestyle.

Table 2.

Results of Hierarchical Regression Analysis, with Family Climate Variables as Dependent Variables.

\begin{tabular}{|c|c|c|c|c|c|c|c|c|}
\hline & Bal. Coh. & Bal. Flex. & Disengag. & Enmes. & Rigid & Chaotic & Communic. & Family sat. \\
\hline \multicolumn{9}{|l|}{ Step 1: Controls } \\
\hline Sex & -.06 & .03 & $.19 * *$ & $.27 * * *$ & $.17^{* *}$ & $.16^{*}$ & -.02 & .05 \\
\hline Age & .02 & .03 & -.11 & -.05 & $-.14 *$ & $-.22 * *$ & .12 & .00 \\
\hline Education & .08 & .03 & -.09 & -.09 & -.01 & .01 & .05 & .07 \\
\hline Material & .09 & .08 & -.04 & -.01 & -.01 & -.05 & .05 & $.13^{*}$ \\
\hline No. of child. & -.02 & .06 & .04 & -.01 & $.15^{*}$ & .03 & .01 & .04 \\
\hline $\mathrm{R}^{2}$ Step 1 & .02 & .01 & .04 & .07 & .04 & .05 & .02 & .03 \\
\hline \multicolumn{9}{|c|}{ Step 2: Controls + Creativity } \\
\hline Sex & -.08 & -.01 & $.21 * * *$ & $.29 * * *$ & $.17^{* *}$ & $.18^{* *}$ & -.05 & .01 \\
\hline Age & .03 & .05 & $-.13^{*}$ & -.07 & $-.14 *$ & $-.23 * * *$ & $.14^{*}$ & .02 \\
\hline Education & .03 & -.02 & -.07 & -.08 & -.03 & .04 & -.01 & .01 \\
\hline Material & .01 & -.02 & .01 & .02 & -.03 & .02 & -.05 & .01 \\
\hline No. of child. & -.02 & .05 & .05 & -.00 & $.15^{*}$ & .04 & -.00 & .03 \\
\hline CSE & $.28 * * *$ & $.38 * * *$ & $-.23 * * *$ & $-.19 * * *$ & .03 & $-.26 * * *$ & $.34 * * *$ & $.40 * * *$ \\
\hline $\mathrm{CPI}$ & $.15^{* *}$ & .11 & -.05 & .03 & .00 & $-.14^{*}$ & $.21^{* * *}$ & $.31 * * *$ \\
\hline Cr. Act & .08 & .04 & .03 & .07 & .10 & .03 & .08 & .02 \\
\hline $\mathrm{R}^{2}$ Step 2 & .11 & .15 & .05 & .04 & .01 & .08 & .17 & .24 \\
\hline $\mathrm{R}^{2}$ Step $1+$ Step 2 & .13 & .16 & .09 & .11 & .05 & .12 & .19 & .27 \\
\hline
\end{tabular}

Note. $N=303$. Sex coded 1 = woman, 2 = man; CSE = Creative Self-Efficacy, CPI = Creative Personal

Identity; Creat. Act = Creative Activity; Bal. Coh. = Balanced Cohesion; Bal. Flex. = Balanced Flexibility;

Diseng. = Disengagement; Enmes. = Enmeshed; Rigid. = Rigidity; Chaotic = Chaos; Communic. =

Communication; Family. Sat = Family Satisfaction.

${ }^{*} p<.05, * * p<.01, * * * p<.001$ 
A similar model, estimated for creative climate factors, yielded similar results. Controls were generally unrelated to creative climate characteristics, apart from the educational level that positively predicted the encouragement of novelty. Overall, however, the models with controls as predictors were not significant and explained only about $1 \%-3 \%$ of creative climate factors variability.

A second step, with CSE, CPI, and creative activity, contributed significantly in terms of the variance explained with $\Delta R^{2}$ from .02 to .12 . Similarly, as in the previous case, CSE was positively associated with encouragement novelty, fantasy, and supporting perseverance, while negatively linked with encouragement nonconformity. CPI explained a unique portion of the variability in encouragement novelty and supporting perseverance while being independent of encouraging nonconformity and encouraging fantasy. Creative activity was positively linked only to encouraging fantasy.

\section{Table 3.}

Results of Hierarchical Regression Analysis, with Creative Climate Variables as Dependent Variables.

\begin{tabular}{|c|c|c|c|c|}
\hline & Enc. Nov. & Enc. Nonc. & Supp. Persev. & Enc. Fantas. \\
\hline \multicolumn{5}{|l|}{ Step 1: Controls } \\
\hline Sex & -.01 & -.04 & -.08 & -.04 \\
\hline Age & .00 & .03 & .00 & -.01 \\
\hline Education & $.17^{* *}$ & .03 & .07 & .08 \\
\hline Material & .00 & .11 & -.03 & -.01 \\
\hline No. of child. & .00 & -.05 & .01 & .02 \\
\hline $\mathrm{R}^{2}$ Step 1 & .03 & .02 & .01 & .01 \\
\hline \multicolumn{5}{|c|}{ Step 2: Controls + Creativity } \\
\hline Sex & -.03 & -.02 & -.10 & -.06 \\
\hline Age & .01 & .02 & .02 & -.01 \\
\hline Education & $.12^{*}$ & .03 & .03 & .04 \\
\hline Material & -.08 & $.14^{*}$ & -.10 & -.08 \\
\hline No. of child. & .00 & -.05 & .01 & .02 \\
\hline CSE & $.28 * * *$ & $-.14 *$ & $.26 * * *$ & $.21 * * *$ \\
\hline $\mathrm{CPI}$ & $.14^{*}$ & -.06 & $.13^{*}$ & .11 \\
\hline Cr. Act & .12 & .09 & .01 & $.16^{* *}$ \\
\hline $\mathrm{R}^{2}$ Step 2 & .12 & .02 & .08 & .10 \\
\hline $\mathrm{R}^{2}$ Step 1 + Step 2 & .15 & .04 & .09 & .11 \\
\hline
\end{tabular}

Note. $N=303$, Sex coded 1 = woman, 2 = man; CSE = Creative Self-Efficacy, CPI = Creative Personal

Identity; Creat. Act $=$ Creative Activity; Enc. Nov. = Encouragement Novelty; Enc. Nonc. $=$ Encouragement Nonconformity; Supp. Persev. $=$ Support for Perseverance; Enc. Fantas. = Encouragement Fantasy. 
Parents' creative self-belief

${ }^{*} p<.05, * * p<.01, * * * p<.001$

Our variable-centered analyses provided a consistent yet not very compelling pattern. Although creativity-related variables tended to be positively associated with family social functioning and climate for creativity, the effect size of these links was generally weak-to-moderate, only rarely (family satisfaction) explaining the robust portion of its variability. However, given that family factors tend to cluster and form a more complex pattern of styles, we decided to provide an additional set of analysesthis time person-centered. To this end, we conducted a number of latent profile analyses in MPlus 8.1, with family lifestyle factors and creative climate factors as criteria of differentiation of the latent profiles. We tested three solutions - consisting of 2, 3, and 4 latent profiles. In deciding which solution should be saved for further analyses, we used both statistical criteria (sample size adjusted Bayesian Information Criteria [SSA BIC], Lo-Mendell-Rubin Likelihood Ratio Test [LRT], and entropy) as well as factors interpretability. As demonstrated in Table 4, 2 profiles were significantly better than the 1-profile solution, as illustrated by a significant LRT test. The three-profile solution was characterized by a better fit, as represented by a lower SSA BIC and significant value of LRT. The four-profiles solution held lower SSA BIC than the 3-profiles solution, yet the LRT test has shown that its fit was not significantly better than in the case of three profiles. Therefore, we decided to proceed with a three profiles solution.

Table 4.

Comparison of the Model Fit with 2-3-and-4 Latent Profiles in Latent Profile Analysis

\begin{tabular}{llll}
\hline Solution & SSA BIC & LRT Test & Entropy \\
\hline 2 Profiles & 7905.32 & $881.82^{* * *}$ & 1 \\
3 Profiles & $\mathbf{7 2 4 0 . 2 0}$ & $\mathbf{6 8 8 . 8 9 * *}$ & .92 \\
4 Profiles & 7093.35 & 177.51 & .92 \\
\hline
\end{tabular}

Note. SSA BIC = Sample Size Adjusted Bayesian Information Criterion, LRT = Lo-Mendell-Rubin Likelihood

Ratio Test. The chosen solution was bolded.

$* * p<.01, * * * p<.001$ 
As illustrated in Figure 2 below, the three profiles had clear and distinctive characteristics. The smallest Profile 1 (6\%) was characterized by very high encouragement of nonconformity in parent-child relations, yet this nonconformity was accompanied by very low support for other factors associated with creativity. Therefore, we decided to call this profile "uncreative nonconformists." The two remaining profiles were large: the largest one (52\%) was composed of parents who assessed their families as balanced, were satisfied, and supported creativity of their children. We called this profile "balanced procreatives." The last profile (42\%)-in a sense-reversely mirrored the profile 2 . These parents tended to be disengaged, enmeshed, poor in communicating, and not satisfied with their family life. Their support for the creativity of their children was low or moderate. We called them "disengaged and chaotic."

\section{Figure 2}

Differences in Criteria Factors used in the LPA.

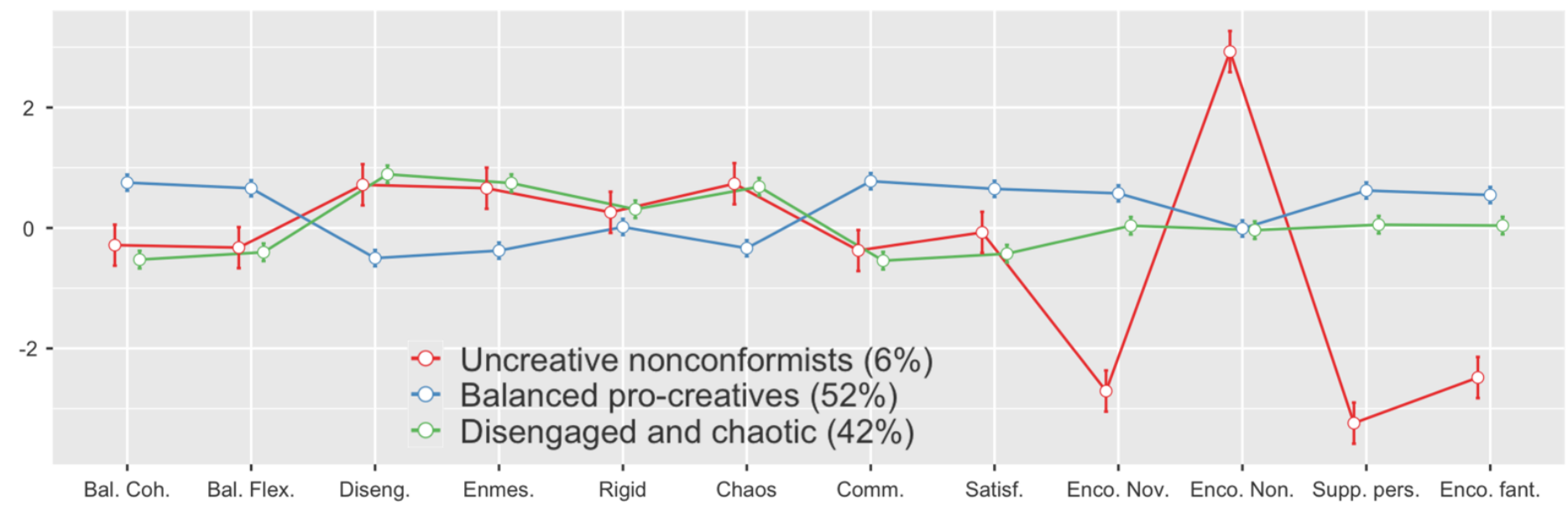

Did the profiles differ in terms of creative self-efficacy, creative personal identity, and creative activity? Our previous, variable-centered analyses suggest so, yet they showed weak-to-moderate effect size. To estimate potential differences between profiles, we conducted three independent analyses of variance (ANOVAs), with CSE, CPI, and creative activity as dependent variables. 
In the case of CSE, we observed significant differences with a moderate effect size, $F(2,300)=$ 23.53, $p<.001, \omega^{2}=.13$. A post-hoc test with Tukey correction for multiple test demonstrated that there was significant difference between balanced pro-creatives $(M=5.38, S D=0.91)$ and disengaged chaotic $(M=4.61, S D=1.03), M_{\text {diff }}=0.76, S E=0.11, p<.001$, Cohen's $d=0.80$. We emphasize the large effect of this differences. Balanced pro-creatives also scored higher than uncreative nonconformists $(M=4.87, S D$ $=0.74)$, yet this difference did not survive Tukey correction $\left(M_{\text {diff }}=-0.51, S E=0.23, p=.079\right.$, Cohen's $d=$ -0.57). There were no differences between the profiles of disengaged and chaotic and uncreative nonconformists $\left(M_{\text {diff }}=0.26, S E=0.24, p=.52\right.$, Cohen's $d=0.26$ ) (See also upper left panel, Figure 3 ).

In the case of $\mathrm{CPI}$, ANOVA demonstrated a significant omnibus effect with robust effect size, $F(2$, $300)=18.57, p<.001, \omega^{2}=.10$. Similarly as in the previous case, there was a statistically significant difference between balanced pro-creatives $(M=5.32, S D=0.96)$ and disengaged and chaotic $(M=4.57$, $S D=1.18), M_{\text {diff }}=0.75, S E=0.12, p<.001$, Cohen's $d=0.71$. Balanced pro-creatives tended to score higher than uncreative nonconformists $(M=4.80, S D=0.67)$, yet this difference did not survive Tukey correction, $M_{\text {diff }}=-0,53, S E=0.26, p=.11$, Cohen's $\left.d=-0.56\right)$. There were no differences between disengaged and chaotic and uncreative nonconformists ( $M_{\text {diff }}=0.22, S E=0.26, p=.67$, Cohen's $d=0.20$ ) (see upper right panel of Figure 3).

In the case of creative activity, the overall effect was significant, yet weaker in terms of the effect size, $F(2,300)=7.76, p<.001, \omega^{2}=.043$. Balanced pro-creatives $(M=1.69, S D=0.46)$ reported significantly higher creative activities than disengaged and chaotic $(M=1.47, S D=0.47), M_{\text {diff }}=0.22, S E$ $=0.06, p<.001$, Cohen's $d=0.48$, but they did not differ from uncreative nonconformists $(M=1.66, S E=$ $0.67), M_{\text {diff }}=-0.03, S E=0.12, p=.96$, Cohen's $d=-0.07$. Disengaged and chaotic and uncreative nonconformists did not differ in terms of creative activity either ( $M_{\text {diff }}=0.19, S E=0.12, p=.26$, Cohen's $d=0.38$ ) (see lower panel of Figure 3 below).

\section{Figure 3}


Differences in CSE (upper left panel), CPI (upper right panel), and Creative Activity (lower panel)

between Three Latent Profiles.
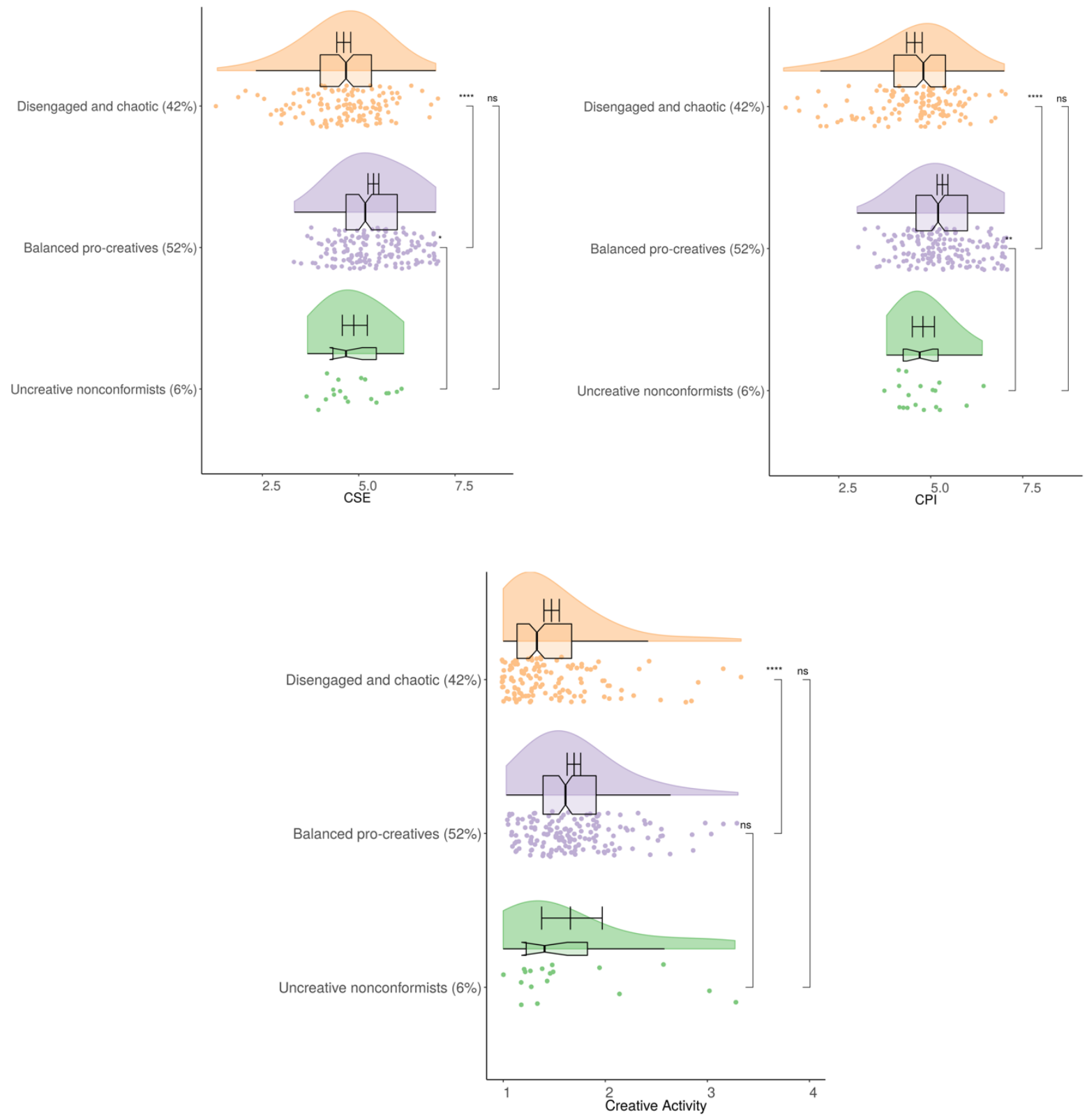

Discussion 
In this study, we sought to understand better whether and if so then which parents' creativityrelated characteristics (i.e., creative self-beliefs and their creative activities) are related to family lifestyle, considered as family social functioning (cohesion, flexibility, communication, and family satisfaction) as well as climate for creativity in the family (encouragement to experience novelty and varieties, encouragement to nonconformism, support of perseverance in creative efforts, encouragement to fantasize). As far as we are aware, our study was the first to test how parents' creativity predicts such a comprehensively operationalized family lifestyle. Previous studies focused on one of these specific areas namely either on the social context of family functioning (Bomba et al., 1991; Chan, 2005; Gardner \& Moran, 1990) or on the climate for creativity built in the home environment (e.g., Gralewski \& Jankowska, 2020; Kwaśniewska \& Lebuda, 2017). Moreover, the relationship between parents' creative self-efficacy and their behaviors that may support their offspring's creativity has not yet been analyzed, while its importance seems natural.

The results of this might be summarized in three key findings. Firstly, creativity-related characteristics of parents are positively associated with positive aspects of family lifestyle. Socondly, creative self-beliefs of parents, especially their CSE, predicts both domain-general dimensions of positive family and domain-specific factors related to creativity. And finally, there are latent profiles of parents that have distinctive characteristics, and systematically differ from one another in terms of creative selfefficacy, creative personal identity, and creative activity.

CSE was a consistent predictor of balanced cohesion, flexibility, family satisfaction, and communication. At the same time, it was negatively linked to the family's problematic functioning (i.e., disengagement, feeling enmeshed and chaotic situation in the family). CPI positively predicted balanced cohesion, communication, and family satisfaction while being negatively related to a chaotic lifestyle. We expected that parents' creative self-beliefs and real-life creative activities would be more important for family lifestyle measured in a specific domain (i.e., for the climate for creativity in the parent-child 
relationship). Contrary to predictions, parents' actual creative activities were unrelated to the family lifestyle even when family lifestyle was assessed in domain-specific factors related to creativity. The creative activity turned out to be positively related, but not very strongly, only to encouraging children to use fantasy. There are two possible explanations for this result. First, it seems most likely that parents' creative activity may be related to family lifestyle, provided that this activity is undertaken with other family members, including children (for example, creative leisure activities, see Hegarty, 2009). Overall, leisure experiences play a vital role in family lifestyle because they build social relationships, positive emotions, cognitive stimulation, self-expression, and creativity (Agate et al., 2009; Tinsley \& Eldredge, 1995). Secondly, this effect may be due to the age of the children whose parents participated in our study. Imaginative play of preschool-age and early school-age children is less dependent on props than in previous developmental stages; it becomes more abstract and creative (Jankowska \& Omelańczuk, 2018). Maybe this is a clear symptom of children's creativity for parents who undertake creative activities themselves and therefore make efforts to support creative fantasizing in play.

To better understand the relationships between parents' creativity-related factors and family lifestyle dimensions, we used a person-centered approach: a latent profile analysis. Three profiles that emerged were named: Uncreative Nonconformists, Balanced Pro-Creatives, and Disengaged and Chaotic. Each of these profiles showed a different pattern of correlates with family lifestyle variables. Parents who formed the Balanced Pro-Creatives profile assessed their family as balanced, enjoyed higher satisfaction with their family life, and declared support for the offspring's creativity. In contrast, a slightly smaller proportion of the Disengaged and Chaotic profiles reported a more problematic family system (enmeshed or disengaged relationships, poor family communication, and dissatisfaction with family relationships) and declared support for children's creativity, but to a lesser extent. Juxtaposing of these two profiles suggests that both balanced relationship with one's own family and disharmony within the family system (Olson et al., 2019) might be associated with a family creativity-fostering 
environment (Harrington, et al., 1987; Kwaśniewska, et al., 2018; Rogers, 1954). Thus, it suggests two distinct paths to fostering creativity and building a creative lifestyle within the familial context. This finding corresponds with previous research, which on the one hand shows that families that provide warmth, support, and acceptance (probably a well-functioning family environment) are associated with children's creativity and creative achievements in one's later life (Gute et al., 2008; Harrington et al., 1987), yet on the other that creative people often come from families that are anything but harmonious (e.g., Chan, 2005; Olszewski-Kubilius, 2000). A recent study also provides empirical support for these two seemingly contradictory family theories in predicting creativity (i.e., the supportive- autonomy parental theory and distance-conflict parental theory, see Guo et al., 2021).

The identified profiles were characterized by statistically significant and theoretically meaningful differences in CSE, CPI, and declared everyday creativity. In the case of creative self-beliefs, parents classified into the Balanced Pro-Creatives profile hold substantially higher CPE and CPI than parents from the Disengaged and Chaotic profile. There were no differences between the profiles of Disengaged and Chaotic and Uncreative Nonconformists, as well as Uncreative Nonconformists and Balanced ProCreatives. Parents' creative activities formed the other creativity-related facet that displayed statistically significant differences across the latent profiles in this study. Representatives of the Balanced ProCreatives group reported higher engagement in creative activities than Disengaged and Chaotic ones. Similarly as in the previous case, we found no other statistically significant differences between the identified profiles in terms of the declared creative activity. These results partially confirm that parents with a positive attitude towards creativity are more likely to nurture their children's creativity (Pugsley \& Acar, 2018). In that sense, the highest scores for all creativity-related variables seen in the Balanced ProCreatives profile showed a similar pattern of relationships as in research with teachers (e.g., Cayirdag, 2017; Dilekli \& Tezci, 2016; Ozkal, 2014), which we mentioned in the introduction. This similarity only partially explains our findings, but it does indicate that if parents believe in their ability to deal with 
Parents' creative self-belief

creative challenges, and creativity is essential to them, they put more effort into their children's creative development.

\section{Limitations and Future Directions}

This investigation suffers from a few limitations that should be addressed in future studies. The first one is that all measures used in our study are self-reporting instruments. Although we emphasize that all main variables we were interested in are traditionally investigated using questionnaires, it is worth considering that this type of assessment is prone to some problems like social desirability bias or common method variance.

The second limitation is that we obtained all information only from the parents' perspective. Future research should include other informants, such as children or outside observers. Including children in the study would allow them to compare their views with parents' judgments and assess the relationship between parents' beliefs, the family environment they arrange, and their children's abilities, beliefs, and creative behaviors. As we did not examine children's creativity, we can only assume, based on previous research, that chosen aspects of family life support children's creativity development. The future longitudinal studies could help understand how parental' creativity-related characteristics and family environment influence changes in children's abilities and beliefs crucial for creative potential realization.

Finally, we note that we utilized an instrument originally designed to measure domain-general creative-self-efficacy and creative personal identity. However, given that creative self-beliefs are highly dynamic and task-related (Beghetto \& Karwowski, 2017), future research would benefit from measuring how people value creativity in their parenting roles and how they judge their ability to deal with parenting challenges creatively. Moreover, we encourage future researchers to employ more than one type of creativity assessment to uncover a more comprehensive picture of parental creativity. 
Parents' creative self-belief

\section{References}

Abuhassàn, A., \& Bates, T. C. (2015). Grit: Distinguishing effortful persistence from conscientiousness. Journal of Individual Differences, 36(4), 205-214. https://doi.org/10.1027/1614-0001/a000175

Agate, J. R., Zabriskie, R. B., Agate, S. T., \& Poff, R. (2009). Family Leisure Satisfaction and Satisfaction with Family Life. Journal of Leisure Research, 41(2), 205-223. https://doi.org/10.1080/00222216.2009.11950166

Bandura, A. (1997). Self-efficacy: The exercise of control. Macmillan.

Batey, M., \& Furnham, A. (2006). Creativity, Intelligence, and Personality: A Critical Review of the Scattered Literature. Genetic, Social, and General Psychology Monographs, 132, 355-429.

http://dx.doi.org/10.3200/MONO.132.4.355-430

Beghetto, R. A. (2006). Creative Self-Efficacy: Correlates in Middle and Secondary Students. Creativity Research Journal, 18(4), 447-457. https://doi.org/10.1207/s15326934crj1804_4

Beghetto, R., \& Kaufman, J. (2007). Toward a broader conception of creativity: A case for "mini-c" creativity. Psychology of Aesthetics, Creativity, and the Arts, 1(2), 73-79. https://doi.org/10.1037/1931-3896.1.2.73

Beghetto, R. A., \& Karwowski, M. (2017). Toward untangling creative self-beliefs. In M. Karwowski \& J. C. Kaufman (Eds.), The creative self: Effects of self- efficacy, mindset and identity. (pp. 4-24). Academic Press.

Beghetto, R. A., Karwowski, M., \& Reiter-Palmon, R. (2020). Intellectual risk taking: A moderating link between creative confidence and creative behavior? Psychology of Aesthetics, Creativity, and the Arts. Advance online publication. https://doi.org/10.1037/aca0000323

Bereczki, E. O., \& Kárpáti, A. (2018). Teachers' beliefs about creativity and its nurture: A systematic review of the recent research literature. Educational Research Review, 23, 25-56.

https://doi.org/10.1016/j.edurev.2017.10.003 
Parents' creative self-belief

Bomba, A. K., Moran, J. D., \& Goble, C. B. (1991). Relationship Between Familial Style and Creative Potential Of Preschool Children. Psychological Reports, 68, 1323-1326. https://doi.org/10.2466/pr0.1991.68.3c.1323

Carmeli, A., \& Schaubroeck, J. (2007). The influence of leaders' and other referents' normative expectations on individual involvement in creative work. The Leadership Quarterly, 18(1), 35-48. https://doi.org/10.1016/j.leaqua.2006.11.001

Cayirdag, N. (2017). Creativity fostering teaching: Impact of creative self-efficacy and teacher efficacy. Kuram ve Uygulamada Eğitim Bilimleri/Educational Sciences: Theory \& Practice, 17(6), 1959-1975.

Chan, D. W. (2005). Self-perceived creativity, family hardiness, and emotional intelligence of Chinese gifted students in Hong Kong. Journal of Secondary Gifted Education, 16(2-3), 47-56. https://doi.org/10.4219/jsge-2005-471

Chen, B. (2016). The Creative Self-Concept as a Mediator Between Openness to Experience and Creative Behaviour. Creativity. Theories - Research - Applications, 3(2), 408-417. https://doi.org/10.1515/ctra-2016-0024

Choi, J. N. (2004). Individual and contextual predictors of creative performance: The mediating role of psychological processes. Creativity Research Journal, 16, 187-199. https://doi.org/10.1080/10400419.2004.9651452

Dilekli, Y., \& Tezci, E. (2016). The relationship among teachers classroom practices for teaching thinking skills, teacher's self-efficacy towards teaching thinking skills and teaching styles. Thinking Skills and Creativity, 21, 144-151. https://doi.org/10.1016/j.tsc.2016.06.001

Dillon, J. J. (2002). The Role of the Child in Adult Development. Journal of Adult Develop- ment, 9, 267275. https://doi.org/10.1023/A:1020286910678 
Parents' creative self-belief

Freeman, M. (1993). Seeking identity: Township youth and social development. South African Journal of Psychology, 23(4), 157-166. https://doi.org/10.1177/008124639302300401

Gardner, K. G., \& Moran, J. D. (1990). Family adaptability, cohesion, and creativity. Creativity Research Journal, 3(4), 281-286. https://doi.org/10.1080/10400419009534361

Glăveanu, V. P., Karwowski, M., Jankowska, D. M., \& de Saint-Laurent, C. (2017). Creative imagination. In T. Zittoun \& V. P. Glăveanu (Eds.), The Oxford handbook of imagination and culture (pp. 61-86). Oxford University Press.

Goertzel, M. G., Goertzel, V., \& Goertzel, T. G. (1978). 300 eminent personalities. Jossey-Bass.

Goertzel, V., Goertzel, M. G., Goertzel, T. G., \& Hansen, A. (2004). Cradles of eminence: Childhoods of more than 700 famous men and women. Great Potential Press, Inc.

Gralewski, J., \& Jankowska, D. M. (2020). Do parenting styles matter? Perceived dimensions of parenting styles, creative abilities and creative self-beliefs in adolescents. Thinking Skills and Creativity, 38, 100709. doi:10.1016/j.tsc.2020.100709

Guo, J., Zhang, J., \& Pang, W. (2021). Parental warmth, rejection, and creativity: The mediating roles of openness and dark personality traits. Personality and Individual Differences, 168, 110369. https://doi.org/10.1016/j.paid.2020.11036

Gute, G., Gute, D. S., Nakamura, J., \& Csikszentmihályi, M. (2008). The early lives of highly creative persons: the influence of the complex family. Creativity Research Journal, 20(4), 343-357. https://doi.org/10.1080/10400410802391207

Harrington, D. M., Block, J. H., \& Block, J. (1987). Testing aspects of Carl Rogers's theory of creative environments: Child-rearing antecedents of creative potential in young adolescents. Journal of Personality and Social Psychology, 52(4), 851-856. https://doi.org/10.1037/0022-3514.52.4.851

Hegarty, C. B. (2009). The value and meaning of creative leisure. Psychology of Aesthetics, Creativity, and the Arts, 3(1), 10-13. https:// https://doi.org/10.1037/a0014879 
Parents' creative self-belief

Jankowska, D. M., \& Gralewski, J. (under review). The Familial Context of Children's Creativity: Parenting Styles and the Climate for Creativity in Parent-Child Relationship. Creativity Studies.

Jankowska, D. M., \& Karwowski, M. (2019). Family factors and development of creative thinking.

Personality and Individual Differences, 142, 202-206. https://doi.org/10.1016/j.paid.2018.07.030

Jankowska, D. M., \& Omelańczuk, I. (2018). Potential Mechanisms Underlying the Impact of Imaginative Play on Socio-Emotional Development in Childhood. Creativity. Theories - Research Applications, 5(1), 84-103. doi:10.1515/ctra-2018-0006

Jauk, E., Benedek, M., \& Neubauer, A. C. (2014). The road to creative achievement: a latent variable model of ability and personality predictors. European Journal of Personality, 28, 95-105. https://doi.org/10.1002/per.1941

Jaussi, K. S., Randel, A. E., \& Dionne, S. D. (2007). I am, I think I can, and I do: The role of personal identity, self-efficacy, and cross-application of experiences in creativity at work. Creativity Research Journal, 19(2-3), 247-258. https://doi.org/10.1080/10400410701397339

Karwowski, M., \& Beghetto, R. A. (2018). Creative behavior as agentic perspective. Psychology of Aesthetics, Creativity, and the Arts. Advance online publication. http://dx.doi.org/10.1037/aca0000190

Karwowski, M., \& Jankowska, D. (2016). Four faces of creativity at school. In R. A. Beghetto \& J. C. Kaufman (Eds.), Nurturing creativity in the classroom (pp. 337-354). New York, NY: Cambridge University Press.

Karwowski, M., Jankowska, D. M., Lebuda, I., \& Czerwonka, M. (2020). Do parents and children perceive creativity similarly? A dyadic study of creative mindsets. Psychology of Aesthetics, Creativity, and the Arts. Advance online publication. https://doi.org/10.1037/aca0000358 
Parents' creative self-belief

Karwowski, M., \& Lebuda, I. (2016). The big five, the huge two, and creative self-beliefs: A meta-analysis. Psychology of Aesthetics, Creativity, and the Arts, 10(2), 214-232. https://doi.org/10.1037/aca0000035

Karwowski, M., \& Lebuda, I. (2017). Creative Self-Concept: A Surface Characteristic of Creative Personality. In G. J. Feist, R. Reiter-Palmon, \& J. C. Kaufman (Eds.), The Cambridge Handbook of Creativity and Personality Research (pp. 84-101). Cambridge University Press. https://doi.org/10.1017/9781316228036.006

Karwowski, M., Lebuda, I., \& Beghetto, R. A. (2019). Creative Self-Beliefs. In J. C. Kaufman \& R. J. Sternberg (Eds.), The Cambridge Handbook of Creativity (2nd ed., pp. 396-418). Cambridge University Press. https://doi.org/10.1017/9781316979839.021

Karwowski, M., Lebuda, I., \& Wiśniewska, E. (2018). Measuring Creative Self-efficacy and Creative Personal Identity. The International Journal of Creativity and Problem Solving, 26(1), 45-57. Karwowski, M., Lebuda, I., Wiśniewska, E., \& Gralewski, J. (2013). Big Five personality factors as the predictors of creative self-efficacy and creative personal identity: Does gender matter? Journal of Creative Behavior, 47(3), 215-232. https://doi.org/10.1002/jocb.32

Karwowski, M. \& Wiśniewska, E. (in press). Creativity in adulthood. In. J. D. Hoffmann, S. W. Russ, \& J. C. Kaufman (Eds.). The Cambridge Handbook of Lifespan Development of Creativity, Cambridge University Press.

Kaufman, J. C., \& Beghetto, R. A. (2009). Beyond big and little: The Four C Model of creativity. Review of General Psychology, 13, 1-12. https://doi.org/10.1037/a0013688

Kochanska, G., Friesenborg, A. E., Lange, L. A., \& Martel, M. M. (2004). Parents' Personality and Infants' Temperament as Contributors to Their Emerging Relationship. Journal of Personality and Social Psychology, 86(5), 744-759. https://doi.org/10.1037/0022-3514.86.5.744 
Parents' creative self-belief

Kouneski, E. F. (2000). Family Assessment and the Circumplex Model: New Research Developments and Applications. Department of Family Social Science, University of Minnesota.

Kwaśniewska, J. M. (2019). Climate for Creativity: How to Measure It in Parent - Child Relationships? In I. Lebuda \& V. P. Glăveanu (Eds.), The Palgrave Handbook of Social Creativity Research (pp. 93107). Springer International Publishing. https://doi.org/10.1007/978-3-319-95498-1_7

Kwaśniewska, J. M., Gralewski, J., Witkowska, E. M., Kostrzewska, M., \& Lebuda, I. (2018). Mothers' personality traits and the climate for creativity they build with their children. Thinking Skills and Creativity, 27, 13-24. https://doi.org/10.1016/j.tsc.2017.11.002

Kwaśniewska, J. M., \& Lebuda, I. (2017). Balancing Between Roles and Duties - The Creativity of Mothers. Creativity. Theories - Research - Applications, 4(1), 137-158.

https://doi.org/10.1515/ctra-2017-0007

Lebuda, I., \& Csikszentmihalyi, M. (2020). All You Need Is Love: The Importance of Partner and Family Relations to Highly Creative Individuals' Well-Being and Success. The Journal of Creative Behavior, 54(1), 100-114. https://doi.org/10.1002/jocb.348

Lebuda, I., \& Glăveanu, V. P. (2019). Re/searching the Social in Creativity, Past, Present and Future: An Introduction to the Palgrave Handbook of Social Creativity Research. In: Lebuda, I. \& Glăveanu, V. P. (Eds.), The Palgrave Handbook of Social Creativity Research (pp.1-10). London: Palgrave Macmillan.

Lebuda, I., Glăveanu, V. P., \& Jankowska, D. M. (in press). Creativity Development and Culture. In: S. Russ, J. Hoffmann, \& J. C. Kaufman (Eds.), Cambridge Handbook of Lifespan Development of Creativity.

Maccoby, E. E. (1992). The role of parents in the socialization of children: An historical overview. Developmental Psychology, 28(6), 1006-1017. https://doi.org/10.1037/00121649.28.6.1006 
Parents' creative self-belief

MacKinnon, D. W. (1962). The nature and nurture of creative talent. American Psychologist, 17(7), 484495. https://doi.org/10.1037/h0046541

Margasiński, A. (2015). The Polish Adaptation of FACES IV-SOR. Polish Journal of Applied Psychology, 13(1), 43-66. https://doi.org/10.1515/pjap-2015-0025

Michel, M., \& Dudek, S. Z. (1991). Mother-child relationships and creativity. Creativity Research Journal, 4(3), 281-286. https://doi.org/10.1080/10400419109534400

Miller, B. C., \& Gerard, D. (1979). Family influences on the development of creativity in children: An integrative review. The Family Coordinator, 28(3), 295. https://www.jstor.org/stable/581942

Miller, G. W. (2010). Mothering and Creativity. In: A. O'Reilly (Ed.), Encyclopedia of Mothrhood (pp. 832834). Thousand Oaks, California: Sage Publications.

Olson, D. (2011). FACES IV and the Circumplex Model: Validation Study. Journal of Marital and Family Therapy, 37(1), 64-80. https://doi.org/10.1111/j.1752-0606.2009.00175.x

Olson, D. H., Waldvogel, L., \& Schlieff, M. (2019). Circumplex Model of Marital and Family Systems: An Update. Journal of Family Theory \& Review, 11(2), 199-211. https://doi.org/10.1111/jftr.12331

Olszewski-Kubilius, P. (2000). The transition from childhood giftedness to adult creative productiveness: Psychological characteristics and social supports. Roeper Review, 23, 65-71. https://doi.org/10.1080/02783190009554068

Ozkal, N. (2014). Relationship between teachers' creativity fostering behaviors and their self-efficacy beliefs. Educational Research and Reviews, 9(18), 724-733. https://doi.org/10.5897/ERR2014.1816

Pang, W., Lu, Y., Long, H., Wang, Q., \& Lin, L. (2020). Three-generational families: Are they beneficial to Chinese children's creativity? Thinking Skills and Creativity, 35, 100623. https://doi.org/10.1016/j.tsc.2019.100623 
Parents' creative self-belief

Petkus, E., Jr. (1996). The creative identity: Creative behavior from the symbolic interactionist perspective. The Journal of Creative Behavior, 30(3), 188-196. https://doi.org/10.1002/j.21626057.1996.tb00768.x

Plucker, J. A., \& Makel, M. C. (2010). Assessment of creativity. In J. C. Kaufman \& R. J. Sternberg (Eds.), The Cambridge handbook of creativity (p. 48-73). Cambridge University Press. https://doi.org/10.1017/CBO9780511763205.005

Pretz, J. E., \& McCollum, V. A. (2014). Self-perceptions of creativity do not always reflect actual creative performance. Psychology of Aesthetics, Creativity, and the Arts, 8(2), 227-236. https://doi.org/10.1037/a0035597

Prinzie, P., Stams, G. J. J. M., Deković, M., Reijntjes, A. H. A., \& Belsky, J. (2009). The relations between parents' Big Five personality factors and parenting: A meta-analytic review. Journal of Personality and Social Psychology, 97(2), 351-362. https://doi.org/10.1037/a0015823

Pugsley, L., \& Acar, S. (2018). Supporting Creativity Or Conformity? Influence of Home Environment and Parental Factors on the Value of Children's Creativity Characteristics. The Journal of Creative Behavior, jocb.393. https://doi.org/10.1002/jocb.393

Richards, R. (2010). Everyday creativity: Process and way of life-Four key issues. In J. C. Kaufman \& R. J. Sternberg (Eds.), The Cambridge handbook of creativity (p. 189-215). Cambridge University Press. https://doi.org/10.1017/СBO9780511763205.013

Rogers, C. R. (1954). Towards a theory of creativity. ETC: A Review of General Semantics, 11, 249-260.

Russ, S. W., Robins, A. L., \& Christiano, B. A. (1999). Pretended play: Longitudinal prediction of creativity and affect in fantasy in children. Creativity Research Journal, 12(2), 129- 139. https://doi.org/10.1207/s15326934crj1202_5

Si, S., Zhang, S., Yu, Q., \& Zhang, J. (2018). The interaction of DRD2 and parenting style in predicting creativity. Thinking Skills and Creativity, 27, 64-77. https://doi.org/10.1016/j.tsc.2017.11.001 
Sigel, I. E., Dreyer, A., \& McGillicuddy-De Lisi, A. V. (1984). Psychological perspectives of the family. In R. D. Parke, (Ed.), Review of child development research (Vol. 7, pp.42-79). University of Chicago Press. Skinner, E., Johnson, S., \& Snyder, T. (2005). Six Dimensions of Parenting: A Motivational Model. Parenting: Science and Practice, 5(2), 175-235. https://doi.org/10.1207/s15327922par0502_3

Sternberg, R. J. (2002). "Creativity as a decision": Comment. American Psychologist, 57(5), 376. https://doi.org/10.1037/0003-066X.57.5.376a

Tanggaard, L. (2015). The Creative Pathways of Everyday Life. The Journal of Creative Behavior, 49(3), 181-193. https://doi.org/10.1002/jocb.95

Tennent, L., \& Berthelsen, D. (1997). Creativity: What does it mean in the family context? Journal of Australian Research in Early Childhood Education, 1, 91-104.

Tierney, P., \& Farmer, S. M. (2002). Creative self-efficacy: Its potential antecedents and relationship to creative performance. Academy of Management Journal, 45(6), 1137-1148. http://dx.doi.org/10.2307/3069429

Tierney, P., \& Farmer, S. M. (2011). Creative self-efficacy development and creative performance over time. Journal of Applied Psychology, 96(2), 277-293. https://doi.org/10.1037/a0020952

Tinsley, H. E., \& Eldredge, B. D. (1995). Psychological benefits of leisure participation: A taxonomy of leisure activities based on their need-gratifying properties. Journal of Counseling Psychology, 42(2), 123-132. https://doi.org/10.1037/0022-0167.42.2.123

Wei, T., Simko, V., Levy, M., Xie, Y., Jin, Y., \& Zemla, J. (2017). Package 'corrplot'. Statistician, 56(316), e24. Wright, C \& Wright, S (1986). A conceptual framework for examining the family's influence on creativity. Family Perspective, 20(2), 127-136. 